Performance of Europium-Doped Strontium lodide, Transparent Ceramics and Bismuth-loaded Polymer Scintillators

N. J. Cherepy, S. A. Payne, B. W. Sturm, S. P. O'Neal, Z. M. Seeley, O. B. Drury, L. K. Haselhorst, B. L. Rupert, R. D. Sanner, P. A. Thelin, S. E. Fisher, R. Hawrami, K. S. Shah, A. Burger, J. O. Ramey, L. A. Boatner

September 1, 2011

SPIE

San Diego, CA, United States

August 21, 2011 through August 26, 2011 
This document was prepared as an account of work sponsored by an agency of the United States government. Neither the United States government nor Lawrence Livermore National Security, LLC, nor any of their employees makes any warranty, expressed or implied, or assumes any legal liability or responsibility for the accuracy, completeness, or usefulness of any information, apparatus, product, or process disclosed, or represents that its use would not infringe privately owned rights. Reference herein to any specific commercial product, process, or service by trade name, trademark, manufacturer, or otherwise does not necessarily constitute or imply its endorsement, recommendation, or favoring by the United States government or Lawrence Livermore National Security, LLC. The views and opinions of authors expressed herein do not necessarily state or reflect those of the United States government or Lawrence Livermore National Security, LLC, and shall not be used for advertising or product endorsement purposes. 


\title{
Performance of Europium-Doped Strontium Iodide, Transparent Ceramics and Bismuth-loaded Polymer Scintillators
}

\author{
N.J. Cherepy*, S.A. Payne, B.W. Sturm, S.P O’Neal, Z.M Seeley, O.B. Drury, L.K. Haselhorst, \\ B.L. Rupert, R.D. Sanner, P.A. Thelin, S.E. Fisher \\ Lawrence Livermore National Laboratory, 7000 East Ave, Livermore, CA 94550, USA \\ R. Hawrami, K.S. Shah, Radiation Monitoring Devices, Watertown, MA 02472 \\ A. Burger, Fisk University, Nashville, TN 37208, USA \\ J. O. Ramey, L.A. Boatner, Oak Ridge National Laboratory, Oak Ridge, TN 37831 USA
}

\begin{abstract}
Recently discovered scintillators for gamma ray spectroscopy, single crystal $\operatorname{SrI}_{2}(\mathrm{Eu}), \mathrm{GYGAG}_{(\mathrm{Ce})}$ transparent ceramic and Bismuth-loaded plastics, offer resolution and fabrication advantages compared to commercial scintillators, such as $\mathrm{NaI}(\mathrm{Tl})$ and standard PVT plastic. Energy resolution at $662 \mathrm{keV}$ of $2.7 \%$ is obtained with $\operatorname{SrI}_{2}(\mathrm{Eu})$, while $4.5 \%$ is obtained with $\mathrm{GYGAG}(\mathrm{Ce})$. A new transparent ceramic scintillator for radiographic imaging systems, $\mathrm{GLO}(\mathrm{Eu})$ offers high light yield of 70,000 Photons/MeV, high stopping, and low radiation damage. Implementation of single crystal $\mathrm{SrI}_{2}(\mathrm{Eu})$, Gd-based transparent ceramics, and Biloaded plastic scintillators can advance the state-of-the art in ionizing radiation detection systems.
\end{abstract}

Keywords: Scintillators, strontium iodide, garnets, bixbyites, transparent ceramics, gamma ray spectrometers, radiography scintillators, plastic scintillators

\section{INTRODUCTION}

Rapid unambiguous isotope identification is facilitated by detectors offering high energy resolution gamma ray spectroscopy and large active volumes. Deployment of radioisotope identification detectors (RIIDs) offering energy resolution significantly superior to Thallium-doped Sodium Iodide $\mathrm{NaI}(\mathrm{Tl})$ is now feasible. The single crystal scintillator, $\mathrm{SrI}_{2}(\mathrm{Eu})$, offers energy resolution for gamma spectroscopy comparable to that of Lanthanum Bromide doped with Cerium, $\mathrm{LaBr}_{3}(\mathrm{Ce})$ and considerably better than Thallium-doped Sodium Iodide, $\mathrm{NaI}(\mathrm{Tl})$ [1-3]. Encapsulated 1 in ${ }^{3}$ single crystals of Europium-doped Strontium Iodide, $\mathrm{SrI}_{2}(\mathrm{Eu})$, now routinely provide energy resolution at $662 \mathrm{keV}$ of $<3 \%$.

Transparent ceramics are fully dense monoliths of micron-scale crystallites, formed by sintering high purity ceramic nanopowders, generally of a single pure phase cubic crystal structure [4-7]. While the best energy resolution for gamma ray spectroscopy is obtained with single crystal scintillators, such as $\mathrm{SrI}_{2}(\mathrm{Eu})$ and $\operatorname{LaBr}_{3}(\mathrm{Ce})$, transparent ceramics offer the possibility of low-cost, net-shape fabrication of oxide scintillators, with benefits of mechanical ruggedness, stability in air and radiation hardness. Transparent ceramic Cerium-doped Gadolinium Garnet, GYGAG(Ce), fabricated at LLNL, offers $4.5 \%$ resolution at $662 \mathrm{keV}$ with PMT readout, and with low-noise silicon photodetector readout, $<4 \%$ can be obtained.

Due to their availability in large sizes at low cost, plastic scintillators, generally based on Polyvinyltoluene, PVT, are used in many applications where a higher density material exhibiting a photopeak would be preferred. Recently, we reported that $\mathrm{cm}$-scale Bismuth-loaded plastic scintillators can provide energy resolution of $<9 \%$ at $662 \mathrm{keV}$ [3]. Applications such as neutron-interrogation screening, in which a pulsed neutron source irradiates an object of interest and the resultant capture gamma rays are analyzed to identify the materials comprising the object, require large scintillator detectors with modest energy resolution but fast timing. The Bi-loaded plastic is comprised of elements with low neutron activation, should be formable into very large sizes, and offer adequate stopping and energy resolution for effective performance in this application.

* cherepy1@1lnl.gov; phone 925 424-3492 
For radiographic imaging applications, we are developing transparent ceramic Europium-doped bixbyites [8]. While pure $\mathrm{Lu}_{2} \mathrm{O}_{3}(\mathrm{Eu})$ forms transparent ceramics with low enough optical scatter for some applications when conditions are optimized, a small amount of secondary phase tends to be present, reducing optical transparency. We therefore have been exploring the more phase-stable mixed Bixbyite, Gadolinium Lutetium Oxide, $(\mathrm{Gd}, \mathrm{Lu})_{2} \mathrm{O}_{3}(\mathrm{Eu})$.

\section{EQUIPMENT AND METHODS}

$\mathrm{SrI}_{2}(3 \mathrm{~mol} \% \mathrm{Eu})$ crystals are being grown at RMD, Oak Ridge National Laboratory and Fisk University using the vertical Bridgman method. The crystals are grown in silica ampoules using anhydrous $\mathrm{SrI}_{2}$ beads (Aldrich, 99.9999.999\%) and $\mathrm{EuI}_{2}$ powder (Aldrich, 99.9-99.999\%), as the starting materials [9-11]. Crystals from all three growers have offered similar performance. Eu-doped crystals are cut into a tapered cylinder shape, while undoped $\mathrm{SrI}_{2}$ crystals are used as right cylinders, polished and encapsulated in an aluminum cans at LLNL [12].

Transparent ceramic garnets were formed at LLNL using stoichiometric mixed metal oxide particles synthesized via flame spray pyrolysis (FSP), a nanoparticle production method developed by Pratsinis and co-workers [13] and Laine and co-workers [14]. Synthesis of FSP nanoparticles was carried out at LLNL, as well as by Nanocerox, Inc. The FSP nanoparticles are formed into a green body, vacuum sintered, then hot-isostatic pressed into optically transparent parts [8]. The relative ease with which the GYGAG(Ce) ceramic is formed with high transparency is due to the "intersubstitutional" cations, whereby the three different cation sites of the garnet unit cell may be occupied by more than one of the cations. Similarly, the phase stability of the other transparent ceramic discussed in this paper, $(\mathrm{Gd}, \mathrm{Lu})_{2} \mathrm{O}_{3}(\mathrm{Eu})$, is superior to that of $\mathrm{Lu}_{2} \mathrm{O}_{3}(\mathrm{Eu})$, making it readily formable with excellent transparency.

Polymer scintillators with $40 \mathrm{wt} \%$ Bismuth were formed at LLNL by mixing a Bismuth metallo-organic with monomer and 3\% fluor, heating to melt, and then subsequently polymerizing the homogeneous mixture. Two different fluors were investigated, an Iridium complex, emitting in the green, and diphenylanthracene, emitting in the blue.

Beta radioluminescence employed ${ }^{90} \mathrm{Sr} /{ }^{90} \mathrm{Y}$ source $(\sim 1 \mathrm{MeV}$ average beta energy). Radioluminescence spectra were collected with a Princeton Instruments/Acton Spec 10 spectrograph coupled to a thermoelectrically cooled CCD camera. The scintillation light produced by the samples under excitation with a ${ }^{137} \mathrm{Cs}$ source (662 $\mathrm{keV}$ gamma) or with a ${ }^{226} \mathrm{Ra}$ source was detected by a commercially available Hamamatsu R6231-100 PMT. The signals were shaped with a Tennelec TC 244 spectroscopy amplifier and recorded with an Amptek MCA8000-A multi-channel analyzer for offline analysis. Decay times of scintillator materials were obtained with a Golden Engineering pulsed x-ray source coupled to an oscilloscope. The Scintillator Light Yield Non-proportionality Characterization Instrument, located at LLNL, is based on the Compton Coincidence technique. Details of the instrumentation and use of the data to obtain intrinsic energy resolution estimates may be found in refs. 15 and 16, respectively.

\section{RESULTS AND DISCUSSION}

\subsection{Characteristics of Single Crystal Europium-doped Strontium Iodide}

We are working to identify the properties that make $\mathrm{SrI}_{2}(\mathrm{Eu})$ such a high-performance scintillator. One possible origin of its high light yield of $\sim 80,000$ Photons/MeV is a relatively small bandgap, together with the low phonon frequencies characteristic of iodides that minimize energy loss to phonons during the relaxation of high energy carriers during the cascade. Figure 1 shows the absorption and radioluminescence spectra measured using a 1 mm thick undoped Strontium Iodide crystal. Strong absorbance at $310 \mathrm{~nm}$, with a tail to lower energy, indicates a bandgap of $\sim 4 \mathrm{eV}$. The radioluminescence spectrum is comprised of a small band centered at $400 \mathrm{~nm}$, presumably due to the $\mathrm{SrI}_{2}$ self-trapped exciton, and a "long-wave" band extending through the visible, with peak value at $550 \mathrm{~nm}$, which is likely due to impurity- or defect-mediated emission. Also shown in Figure 1 is the radioluminescence spectrum of a typical Europium-doped Strontium Iodide crystal, dominated by the $\mathrm{Eu}^{2+}$ emission band at $420 \mathrm{~nm}$, along with a small amount of the "long-wave" band. The relative intensity of the "long-wave" band varies considerably from crystal to crystal, as a function of both the $\mathrm{Eu}^{2+}$ doping level and of the crystal purity, and similar effects have been previously reported with other alkaline earth halides, such as $\mathrm{BaI}_{2}(\mathrm{Eu})[9,17]$. In Figure 2, a pulse height spectrum acquired with a ${ }^{137} \mathrm{Cs}$ source using a $13 \mathrm{~cm}^{3} \operatorname{SrI}_{2}(3 \% \mathrm{Eu})$ shows resolution of $2.7 \%$ at $662 \mathrm{keV}$ (shaping time $\left.12 \mu \mathrm{s}\right)$. This performance is comparable to that of Cerium-doped Lanthanum Bromide, with the advantage that $\operatorname{SrI}_{2}(\mathrm{Eu})$ is free of intrinsic radioactivity. 

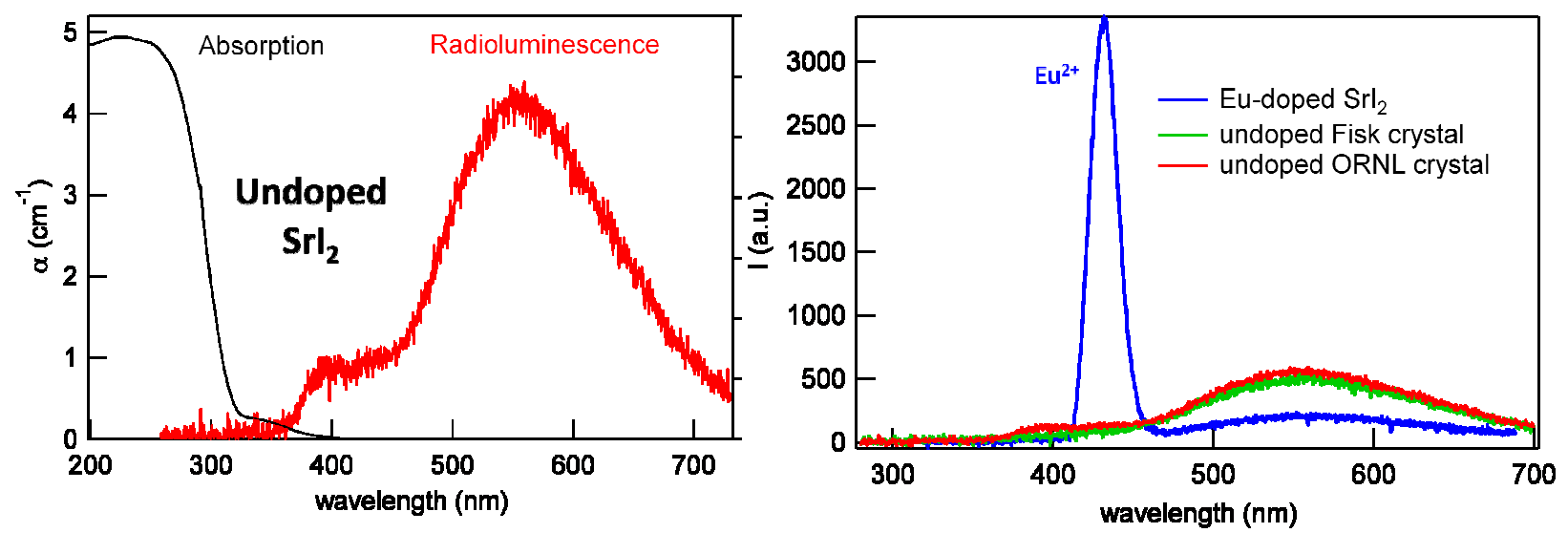

Figure 1. (left) Absorption and beta-excited radioluminescence spectra of and undoped Strontium Iodide crystal. (right) Radioluminescence spectra of Eu-doped and undoped $\mathrm{SrI}_{2}$ crystals. Note that the self-trapped exciton band lies to slightly higher energy than the Eu ${ }^{2+}$ emission, explaining the excellent scintillation efficiency of $\operatorname{SrI}_{2}(\mathrm{Eu})$.

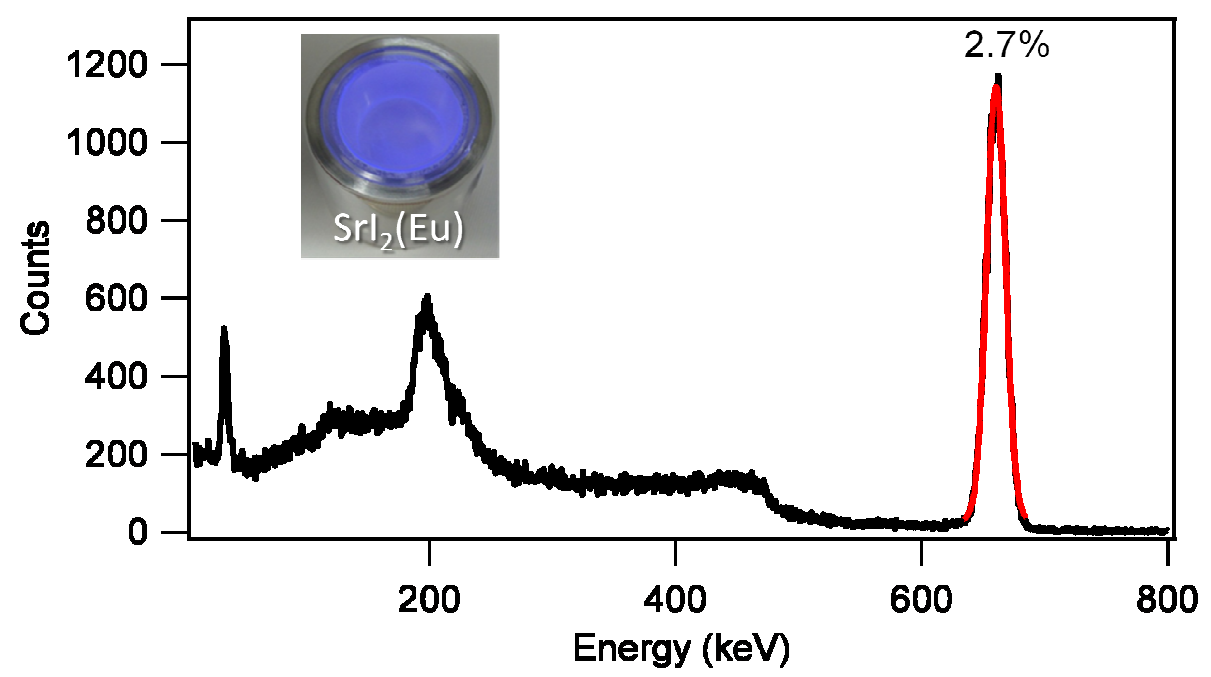

Figure 2. Pulse height spectrum acquired with a ${ }^{137} \mathrm{Cs}$ source using an encapsulated $13 \mathrm{~cm}^{3} \operatorname{SrI}_{2}(3 \% \mathrm{Eu})$ crystal, offering 2.7\% resolution at $662 \mathrm{keV}$. (inset) Photograph of a $13 \mathrm{~cm}^{3}$ encapsulated $\mathrm{SrI}_{2}(\mathrm{Eu})$ crystal under UV illumination.

\subsection{Characteristics of Gadolinium Garnet Ceramic Scintillator}

Gadolinium Yttrium Gallium Aluminum Garnet (GYGAG) transparent ceramics are being developed at LLNL for gamma ray spectroscopy applications [5-7, 18]. Reported values for the bandgaps of Yttrium Aluminum Garnet (YAG) and of Gadolinium Gallium Garnet (GGG) are $6.7 \mathrm{eV} \mathrm{[19]} \mathrm{and} 4.6 \mathrm{eV}$ [20], respectively. The absorption spectra of undoped and Ce-doped GYGAG are shown in Figure 3. Several salient features include the sharp Gd ${ }^{3+}$ absorption lines that lie within the bandgap, and the absorption onset at $230 \mathrm{~nm}$ corresponding to a band gap of $\sim 5.4 \mathrm{eV}$, in good agreement with the bandgap for the mixed garnet GYGAG lying about halfway between those of the line compounds YAG and GGG. Also shown in Figure 3 is the scintillation decay profile for GYGAG(Ce), acquired using pulsed x-ray excitation. The decay exhibits two principal components: the fast time constant of $250 \mathrm{~ns}$ may be assigned to direct 
trapping of excitation on $\mathrm{Ce}^{3+}$, and its subsequent emission, while the slower component, at $\sim 1.7$ microseconds may be assigned to excitation trapping first at $\mathrm{Gd}^{3+}$ and then transferring to $\mathrm{Ce}^{3+}$. The advantage of addition of $\mathrm{Gd}$ to the garnets is the augmentation of their light yield and light yield proportionality [21], however, the total decay is somewhat longer than that of the well-known scintillators $\mathrm{YAG}(\mathrm{Ce})$ or $\mathrm{LuAG}(\mathrm{Ce})$ [see for example ref. 22], due to the mechanism of energy transfer via Gd.
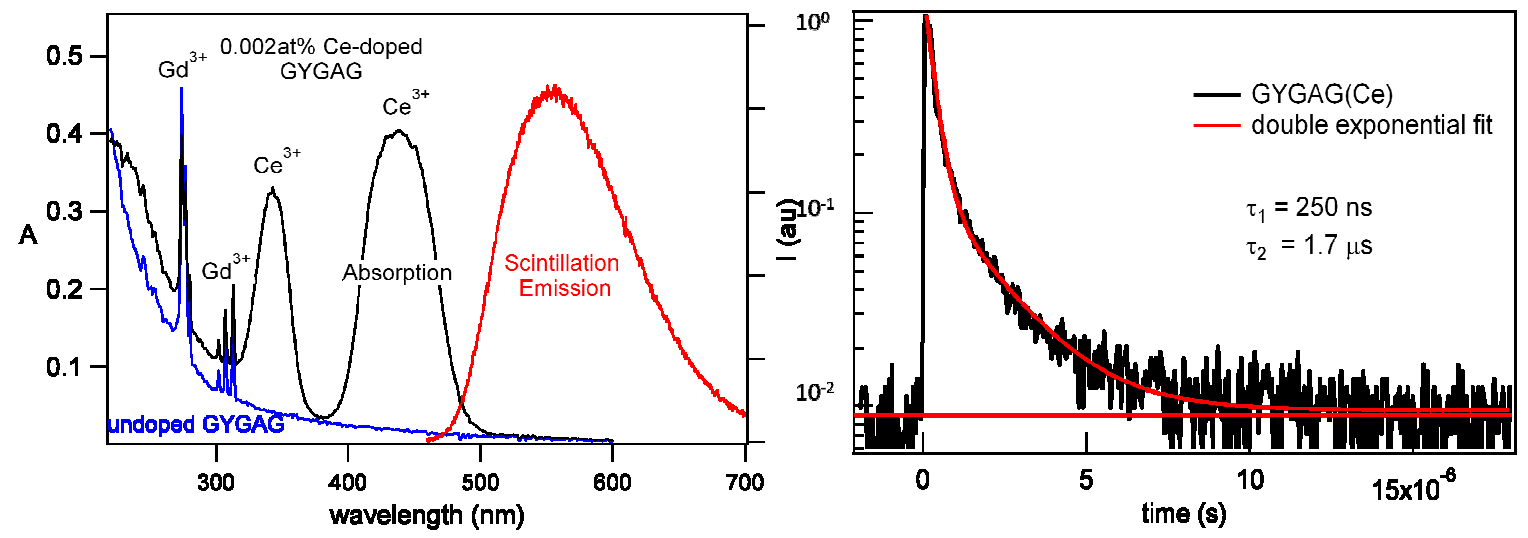

Figure 3. (left) Absorption spectra of two GYGAG ceramics, undoped and Ce-doped, along with the beta-excited radioluminescence spectrum of $\operatorname{GYGAG}(\mathrm{Ce})$. (right) The scintillation decay for $\operatorname{GYGAG}(\mathrm{Ce})$ acquired with pulsed x-ray excitation shows that the scintillation intensity decreases by 100x from the initial value within $4 \mu$ s, the typical shaping time used for this scintillator.

In Figure 4, a pulse height spectrum acquired with a ${ }^{137} \mathrm{Cs}$ source using a cubic-cm size GYGAG(Ce) shows resolution of $4.5 \%$ at $662 \mathrm{keV}$ (shaping time of $4 \mu \mathrm{s}$ ) with PMT readout. This performance is superior to that of $\mathrm{NaI}(\mathrm{Tl})$, which typically offers $6.5 \%$ resolution at $662 \mathrm{keV}$, with the advantage that the oxide transparent ceramic GYGAG(Ce) is mechanically and environmentally robust.

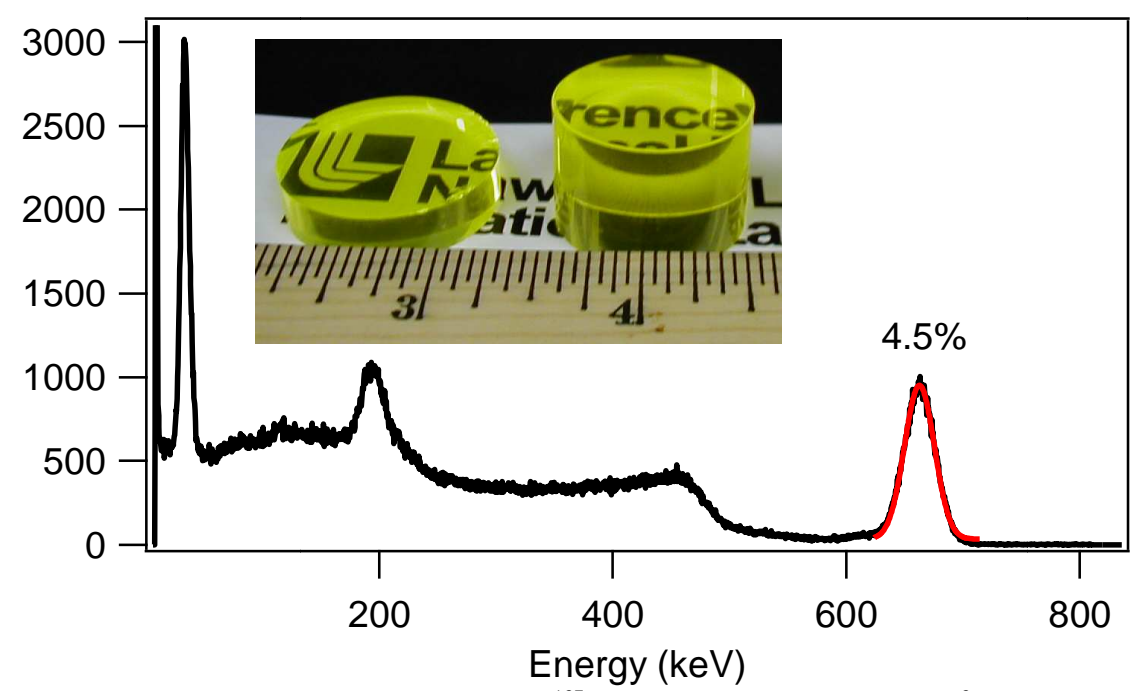

Figure 4. Pulse height spectrum acquired with a ${ }^{137} \mathrm{Cs}$ source shows that a $1 \mathrm{~cm}^{3}$ GYGAG(Ce) transparent ceramic scintillator with PMT readout provides $4.5 \%$ resolution at $662 \mathrm{keV}$. (inset) Photograph of a $5.3 \mathrm{~cm}^{3}$ and a $9.9 \mathrm{~cm}^{3}$ GYGAG(Ce) ceramic. 


\subsection{Comparative Gamma Ray Spectroscopy with $\operatorname{SrI}_{2}(\mathrm{Eu})$, GYGAG(Ce), $\operatorname{LaBr}_{3}(\mathrm{Ce}), \mathrm{NaI}(\mathrm{TI})$ and Germanium}

To study the effect of energy resolution on the ability of detectors to measure and discriminate weak gamma lines within a background, we performed measurements with a ${ }^{226} \mathrm{Ra}$ source, shown in Figure 5 . The ${ }^{226} \mathrm{Ra}$ source has a large number of closely-spaced gamma lines. The spectrum acquired with a mechanically cooled semiconductor Germanium detector displays $>20$ peaks. The energy resolution obtainable with $\operatorname{SrI}_{2}(\mathrm{Eu})$ and $\operatorname{LaBr}_{3}(\mathrm{Ce})$ is adequate to clearly identify about 17 of them-all of the strong lines that are well-separated, as well as several that are weak and closely spaced. The resolution with GYGAG(Ce) is better than with $\mathrm{NaI}(\mathrm{Tl})$, as noted by the narrower peaks, as well as a few features it resolves better than $\mathrm{NaI}(\mathrm{Tl})$, such as the feature at $\sim 400 \mathrm{keV}$.

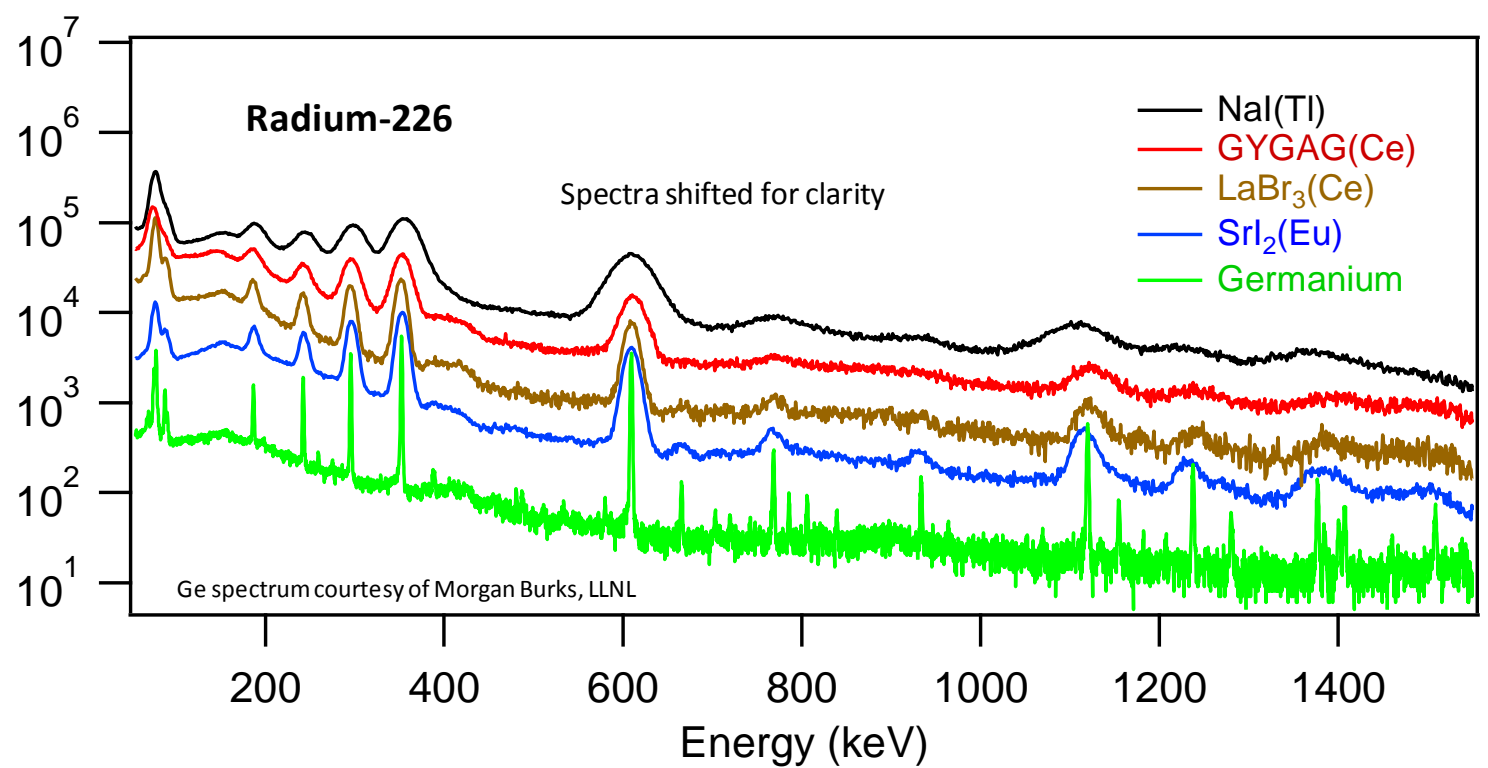

Figure 5. Gamma spectra acquired with a ${ }^{226} \mathrm{Ra}$ source using a mechanically-cooled Germanium detector, and the following scintillators, $\mathrm{SrI}_{2}(\mathrm{Eu}), \mathrm{LaBr}_{3}(\mathrm{Ce}), \mathrm{GYGAG}(\mathrm{Ce})$ transparent ceramic and $\mathrm{NaI}(\mathrm{Tl})$, all with PMT readout, using shaping times adjusted for the best performance with each scintillator.

\subsection{Characteristics of Bismuth-loaded Plastic Scintillators for Gamma Ray Spectroscopy}

We are developing a class of plastic scintillators containing a high loading of a Bismuth organometallic compound, in order to convey high gamma stopping while not degrading the scintillation light yield. Two samples were characterized for their gamma and electron light yield proportionality, shown in Figure 6. The gamma proportionality measurements utilized the following sources: ${ }^{241} \mathrm{Am}(59.5 \mathrm{keV}),{ }^{57} \mathrm{Co},(122 \mathrm{keV}),{ }^{133} \mathrm{Ba}(31.6,81,279.5$ and $356 \mathrm{keV})$, ${ }^{137} \mathrm{Cs}$ (escape peak at 583 and photopeak at $661.7 \mathrm{keV}$ ). The electron non-proportionality was obtained using the Scintillation Light Yield Non-proportionality Characterization Instrument (SLYNCI) [15,16]. The two plastic samples were identical, except that one sample contained 3\% Diphenylanthracene, or DPA, while the other contained 3\% of an Iridium complex fluor known as FIrpic. The scintillation decay for the DPA-doped sample is 14 ns, while the FIrpicdoped sample decays in about $1.25 \mu \mathrm{s}$. It is notable for both the electron and gamma measurement that the sample doped with the Iridium complex exhibits better proportionality. We can estimate that the non-proportionality-limited energy resolution at $662 \mathrm{keV}$ for the DPA- and FIrpic-doped samples is 3.5 and 2.3\%, respectively [21]. Therefore, if this performance can be maintained for large sizes, the DPA-doped material could offer sufficient energy resolution with fast enough timing for use in neutron interrogation applications. The FIrpic-doped material offers potential for high energy resolution gamma spectroscopy, due to the capacity for such Iridium complexes to accept excitation from both singlet and triplet excitons. This mechanism is well-known for applications in Organic Light Emitting Diodes, and also 
previously demonstrated for scintillation [22, 23]. Therefore, the light yield and proportionality of the FIrpic-doped sample is enhanced compared to the DPA-doped material, in which only singlets may be emitted.

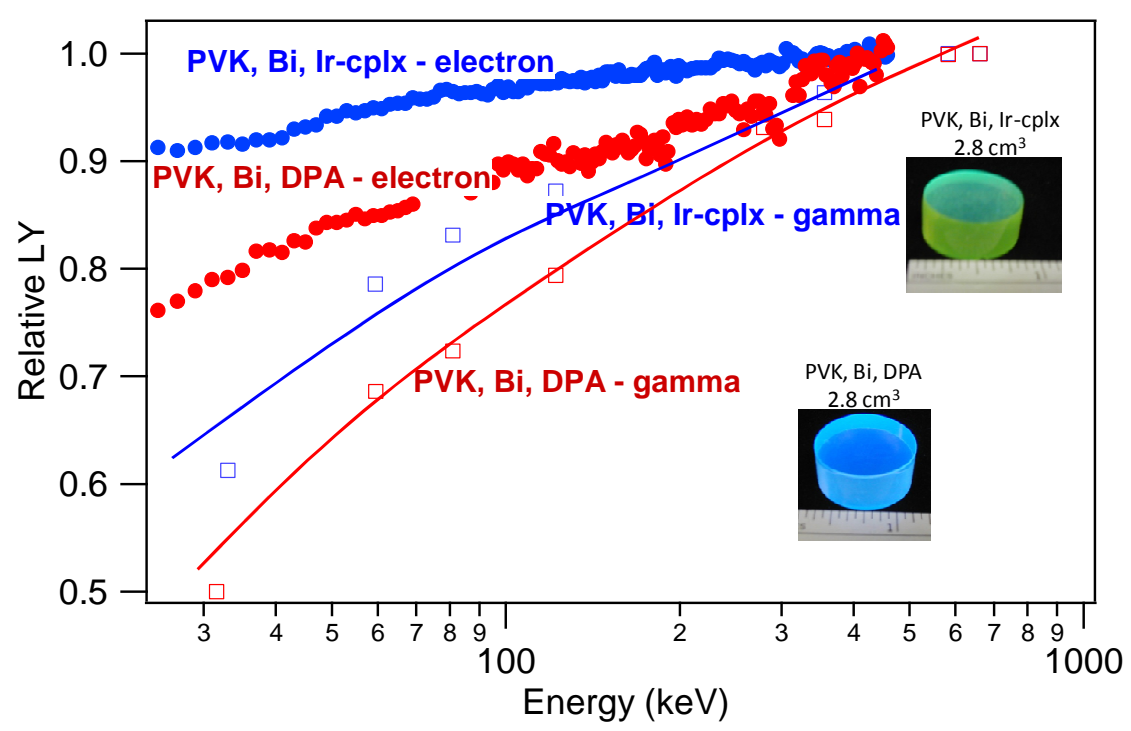

Figure 6. Light yield proportionality obtained with gamma excitation (open symbols and solid lines) and with electron excitation using SLYNCI (closed symbols). The proportionality of the sample using the Iridium complex (spin-orbit couping fluor) is somewhat better than the DPA-doped sample.

\subsection{Characteristics of Gadolinium Lutetium Oxide Bixbyite Radiography Scintillator Ceramic}

Transparent ceramic $\mathrm{Lu}_{2} \mathrm{O}_{3}(\mathrm{Eu})$ is a known material, though achieving acceptable transparency has been a challenge $[9,24]$. We have identified a mixed Bixbyite, $(\mathrm{Gd}, \mathrm{Lu})_{2} \mathrm{O}_{3}(5 \% \mathrm{Eu})$, that is very phase-stable, thus formable with low optical scatter in sheets or voxels for high energy radiography. GLO(Eu) offers high density of $8-9 \mathrm{~g} / \mathrm{cm}^{3}$ and a high light yield of 70,000 Photons/MeV. In Figure 7, the beta excited radioluminescence spectra of standard materials used for scintillator-based radiography $\mathrm{CsI}(\mathrm{Tl}), \mathrm{CdWO}_{4}$ are compared with $\mathrm{GLO}(\mathrm{Eu})$. Standard non-intrusive inspection systems use a millisecond-pulsed $9 \mathrm{MeV}$ Bremsstrahlung x-ray source (average energy $3 \mathrm{MeV}$ ), and readout can be made following a variety of configurations, from lens-based imaging to linear photodiode arrays. The light yield, $\alpha_{\gamma}$ (the attenuation coefficient of $3 \mathrm{MeV}$ x-rays), $\Phi_{\mathrm{PD}}$ (the detection sensitivity of Silicon at the emission maximum of the scintillator) are best with $\mathrm{GLO}(\mathrm{Eu})$, as shown in Table 1 . The radiation hardness of GLO(Eu) was tested by exposure to $450 \mathrm{keV}$ x-rays. No darkening was observed even for the longest exposure, of $10 \mathrm{kGy}$. Use of GLO(Eu) in nondestructive inspection systems could reduce the dose required to achieve accurate radiographs and permit new geometries to be utilized, not readily available with $\mathrm{CsI}(\mathrm{Tl})$ and $\mathrm{CdWO}_{4}$ single crystals.

Table 1. Properties of several optically transparent scintillators used for high energy radiography.

\begin{tabular}{|l|l|l|l|l|l|l|l|}
\hline Scintillator & $\begin{array}{c}\text { Density } \\
\left(\mathbf{g} / \mathbf{c m}^{\mathbf{3}}\right)\end{array}$ & $\begin{array}{c}\boldsymbol{\alpha}_{\mathbf{\gamma}}\left(\mathbf{c m}^{-\mathbf{1}}\right) \text { @ } \mathbf{3} \mathbf{M e V} \\
\mathrm{GLO}\end{array}$ & $\begin{array}{c}\text { Light yield } \\
\mathbf{P h} / \mathbf{M e V}\end{array}$ & $\boldsymbol{\Phi}_{\mathbf{P D}} @ \boldsymbol{\lambda}_{\max }$ & $\begin{array}{c}\text { Principal } \\
\text { decay }(\boldsymbol{\mu} \mathbf{s})\end{array}$ & $\begin{array}{c}\text { Afterglow } \\
(\boldsymbol{\%} \text { @ 100ms })\end{array}$ & Comments \\
\hline $\mathrm{CsI}(\mathrm{Tl})$ & 9.1 & 0.36 & 70,000 & $1.0 @ 611$ & 1000 & 0.01 & No issues \\
\hline $\mathrm{CdWO}_{4}$ & 4.5 & 0.17 & 65,000 & $0.96 @ 550$ & 8 & 0.3 & Degrades \\
\hline
\end{tabular}




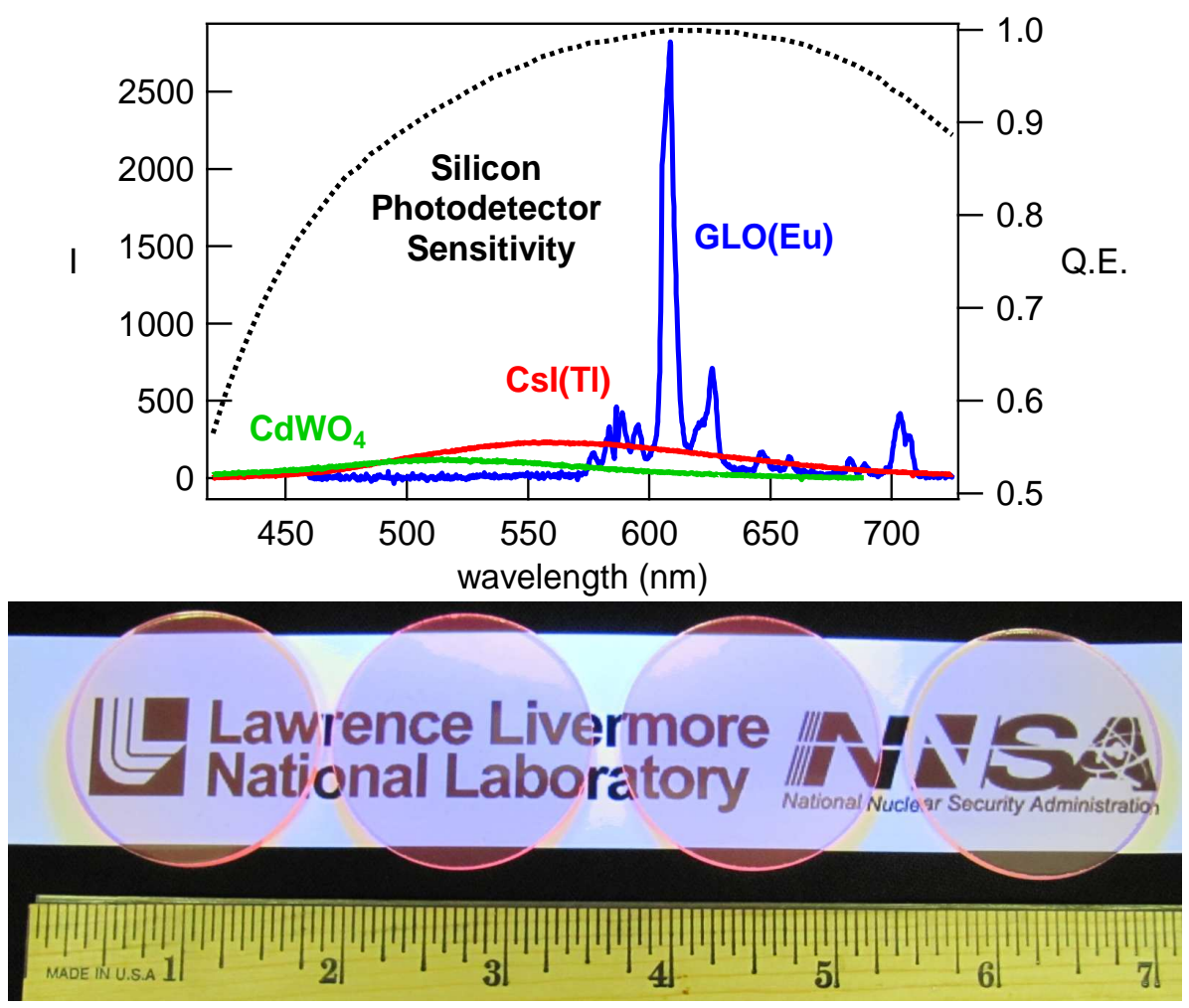

Figure 7. (top) Beta radioluminescence spectra of transparent ceramic GLO(Eu) compared with $\mathrm{CdWO}_{4}$ and $\mathrm{CsI}(\mathrm{Tl})$, spectra may be directly compared and represent their absolute light yields. (bottom) A photograph of four $4.2 \mathrm{~cm}$ diameter by $0.2 \mathrm{~cm}$ thick $\mathrm{GLO}(\mathrm{Eu})$ radiography ceramics in room lights and under weak UV illumination, displaying the orange $\mathrm{Eu}^{3+}$ emission.

\section{CONCLUSIONS}

We have identified several new scintillator materials and are developing them for multiple applications. Among them, the highest light yield, and most proportional material is $\operatorname{SrI}_{2}(\mathrm{Eu})$. Transparent ceramic $\mathrm{GYGAG}(\mathrm{Ce})$ offers high light yield, and gamma spectroscopy with better resolution than $\mathrm{NaI}(\mathrm{Tl})$. We have synthesized and characterized $\mathrm{Bi}$ loaded polymer scintillators that can be used for gamma spectroscopy. High light yields and excellent phase stability are obtained for a new radiography scintillator, $\mathrm{GLO}(\mathrm{Eu})$. We are now optimizing fabrication procedures and scaling up to larger sizes for all of these materials.

\section{ACKNOWLEDGEMENTS}

This work was supported by the Domestic Nuclear Detection Office in the Department of Homeland Security, by the National Nuclear Security Administration, Office of Nonproliferation Research and Development (NA-22) of the U.S.DOE and the US DOE, Office of NNSA, Enhanced Surveillance Subprogram. This work was performed under the auspices of the U.S. Department of Energy by Lawrence Livermore National Laboratory under Contract DE-AC5207NA27344. 


\section{REFERENCES}

[1] E.V.D. van Loef, P. Dorenbos, C.W.E. van Eijk, K. Krämer, H.U. Güdel, "High-energy-resolution scintillator: Ce ${ }^{3+}$ activated $\mathrm{LaBr}_{3}, "$ Appl. Phys. Lett, 79, 1573 (2001).

[2] N.J. Cherepy, S.A. Payne, S.J. Asztalos, G. Hull, J.D. Kuntz, T. Niedermayr, S. Pimputkar, J.J. Roberts, R.D. Sanner, T.M. Tillotson, E. van Loef, C.M. Wilson, K.S. Shah, U.N. Roy, R. Hawrami, A. Burger, L.A. Boatner, W.-S. Choong, "Scintillators with Potential to Supersede Lanthanum Bromide,” IEEE Trans. Nucl. Sci., 56, 873-880 (2009).

[3] N.J. Cherepy, S.A. Payne, B.W. Sturm, J.D. Kuntz, Z.M. Seeley, B.L. Rupert, R.D. Sanner, O.B. Drury, T.A. Hurst, S.E. Fisher, M. Groza, L. Matei, A. Burger, R. Hawrami, K.S. Shah, L.A. Boatner, "Comparative gamma spectroscopy with $\operatorname{SrI}_{2}(\mathrm{Eu})$, GYGAG(Ce) and Bi-loaded plastic scintillators,” IEEE Nuc. Sci. Symp. Conf. Record, p. 1288 - 1291 (2010).

[4] T.Yanagida, H. Takahashi, T. Ito, D. Kasama, T. Enoto, M. Sato, Sh. Hirakuri, M. Kokubun, K. Makishima, T. Yanagitani, H. Yagi, T. Shigeta, T. Ito "Evaluation of Properties of YAG (Ce) Ceramic Scintillators," IEEE Trans. Nucl. Sci., 52, 1836 (2005).

[5] G. Hull, J.J. Roberts, J.D. Kuntz, S.E. Fisher, R.D. Sanner, T.M. Tillotson, A.D. Drobshoff, S.A. Payne, and N.J. Cherepy, "Cedoped single crystal and ceramic Garnets for $\square$ ray detection" Proc. SPIE 6706, 670617 (2007).

[6] N.J. Cherepy, J.D. Kuntz, J.J. Roberts, T.A. Hurst, O.B. Drury, R.D. Sanner, T.M. Tillotson, S.A. Payne, "Transparent Ceramic Scintillator Fabrication, Properties and Applications," Proc. SPIE, 7090, 707917 (2008).

[7] N. J. Cherepy, J. D. Kuntz, Z. M. Seeley, S. E. Fisher, O. B. Drury, B. W. Sturm, T. A. Hurst, R. D. Sanner, J. J. Roberts and S. A. Payne, "Transparent ceramic scintillators for gamma spectroscopy and radiography," Proc. SPIE 7805, 78050I (2010).

[8] Z.M. Seeley, J.D. Kuntz, N.J. Cherepy, S.A. Payne, "Transparent $\mathrm{Lu}_{2} \mathrm{O}_{3}$ :Eu ceramics by sinter and HIP optimization," Optical Mat., 33, 1721-1726 (2011).

[9] N.J. Cherepy, G. Hull, A. Drobshoff, S.A. Payne, E. van Loef, C. Wilson, K. Shah, U.N. Roy, A. Burger, L.A. Boatner, W-S Choong, W.W. Moses "Strontium and Barium Iodide High Light Yield Scintillators," Appl. Phys. Lett. 92, 083508 (2008).

[10] N. J. Cherepy, B. W. Sturm, O. B. Drury; T. A. Hurst. S. A. Sheets, L. E. Ahle, C. K. Saw, M. A. Pearson, S. A. Payne, A. Burger, L. A. Boatner, J. O. Ramey, E. V. van Loef, J. Glodo, R. Hawrami, W. M. Higgins, K. S. Shah, W. W. Moses, "SrI 2 scintillator for gamma ray spectroscopy ," Proc. SPIE, 7449, 7449-0 (2009).

[11] R. Hawrami, A. Burger, L.A. Boatner, E. van Loef, K.S. Shah "Prospects for High Energy Resolution Gamma Ray Spectroscopy with Europium-Doped Strontium Iodide," Mater. Res. Soc. Symp. Proc. Vol. 1164, 1164-L11-04 (2009).

[12] B.W. Sturm, N.J. Cherepy, O.B. Drury, P.A. Thelin, S.E. Fisher, S.A. Payne, A. Burger, L.A. Boatner, J.O. Ramey, K.S. Shah, R. Hawrami, "Effects of Packaging $\mathrm{SrI}_{2}(\mathrm{Eu})$ Scintillator Crystals ," Nucl. Instr. Meth. A, in press (2011).

[13] L. Mädler, H.K. Kammler, R. Mueller, S.E. Pratsinis, "Controlled synthesis of nanostructured particles by flame spray pyrolysis," Aerosol Sci. 33, 369 (2002).

[14] C.R. Bickmore, K.F. Waldner, D.R. Treadwell, R.M. Laine, "Ultrafine Spinel Powders by Flame Spray Pyrolysis of a Magnesium Aluminum Double Alkoxide," J. Am. Ceram. Soc. , 79, 1419-23 (1996).

[15] W.-S. Choong, G. Hull, W.W. Moses, N.J. Cherepy, S.A. Payne, J.D Valentine, "Performance of a facility for measuring scintillator non-proportionality," IEEE Trans. Nucl. Sci., 55 , 1073-1078 (2008).

[16] S.A. Payne, N.J. Cherepy, G. Hull, J.D. Valentine, W.W. Moses, W.-S. Choong, "Nonproportionality of Scintillator Detectors: Theory and Experiment,” IEEE Trans. Nucl. Sci., 56, 2506 - 2512 (2009).

[17] N.J. Cherepy, G. Hull, T.R. Niedermayr, A. Drobshoff, S.A. Payne, U.N. Roy, Y.L. Cui, A. Bhattacharaya, M. Harrison, M.-S. Guo, M. Groza, A. Burger, "Barium iodide single-crystal scintillator detectors," Proc. SPIE 6706, 70616 (2007).

[18] O.B. Drury, N.J. Cherepy, T.A. Hurst, S.A. Payne, "Garnet Scintillator-Based Devices for Gamma-Ray Spectroscopy," IEEE Nuc. Sci. Symp., vol. 1-5, 1585-1587 (2009).

[19] L. Ning, P. A. Tanner, V.V. Harutunyan, E. Aleksanyan,V.N. Makhov, M. Kirm, "Luminescence and excitation spectra of YAG:Nd ${ }^{3+}$ excited by synchrotron radiation," J. Luminescence 127, 397-403 (2007).

[20] S. Mahlik, B. Kukliński, M. Grinberg, L. Kostyk and O. Tsvetkova, "Luminescence and Luminescence Kinetics of $\mathrm{Gd}_{3} \mathrm{Ga}_{5} \mathrm{O}_{12}$ Polycrystals Doped with $\mathrm{Cr}^{3+}$ and $\mathrm{Pr}^{3+}$," Acta Phys. Pol. A, 117 (2010).

[21] S.A. Payne, et al, this proceedings volume.

[22] N. Cherepy, J. Kuntz, T. Tillotson, D. Speaks, S.A. Payne, B. Chai, "Single Crystal and Transparent Ceramic Lutetium Aluminum Garnet Scintillators," Nucl. Instr. Meth. A, 579, 38 (2007).

[23] C. Adachi, M. A. Baldo, M. E. Thompson, S. R. Forrest, J. Appl. Phys. 90, 5048 (2001).

[24] H. Campbell and B. K. Crone, "Efficient Plastic Scintillators Utilizing Phosphorescent Dopants" App. Phys. Lett. 90, 012117, (2007).

[25] A. Lempicki, C. Brecher, P. Szupryczynski, H. Lingertat, V. Nagarkar, S. Tipnis, S. Miller, "A new lutetia-based ceramic scintillator for X-ray imaging,” Nuc. Inst. Meth. Phys. Res. A 488, 579 (2002). 